\title{
On the Status of Rhacophorus prasinatus Mou, Risch, and Lue
} (Anura: Rhacophoridae)

\author{
WEN-HAO CHOU \\ Department of Zoology, National Museum of Natural Science, Taichung, Taiwan 40419, \\ Republic of China
}

Key Words: Amphibia, Anura, Rhacophoridae, Polypedates prasinatus, Rhacophorus smaragdinus, Taiwan, New Combination.

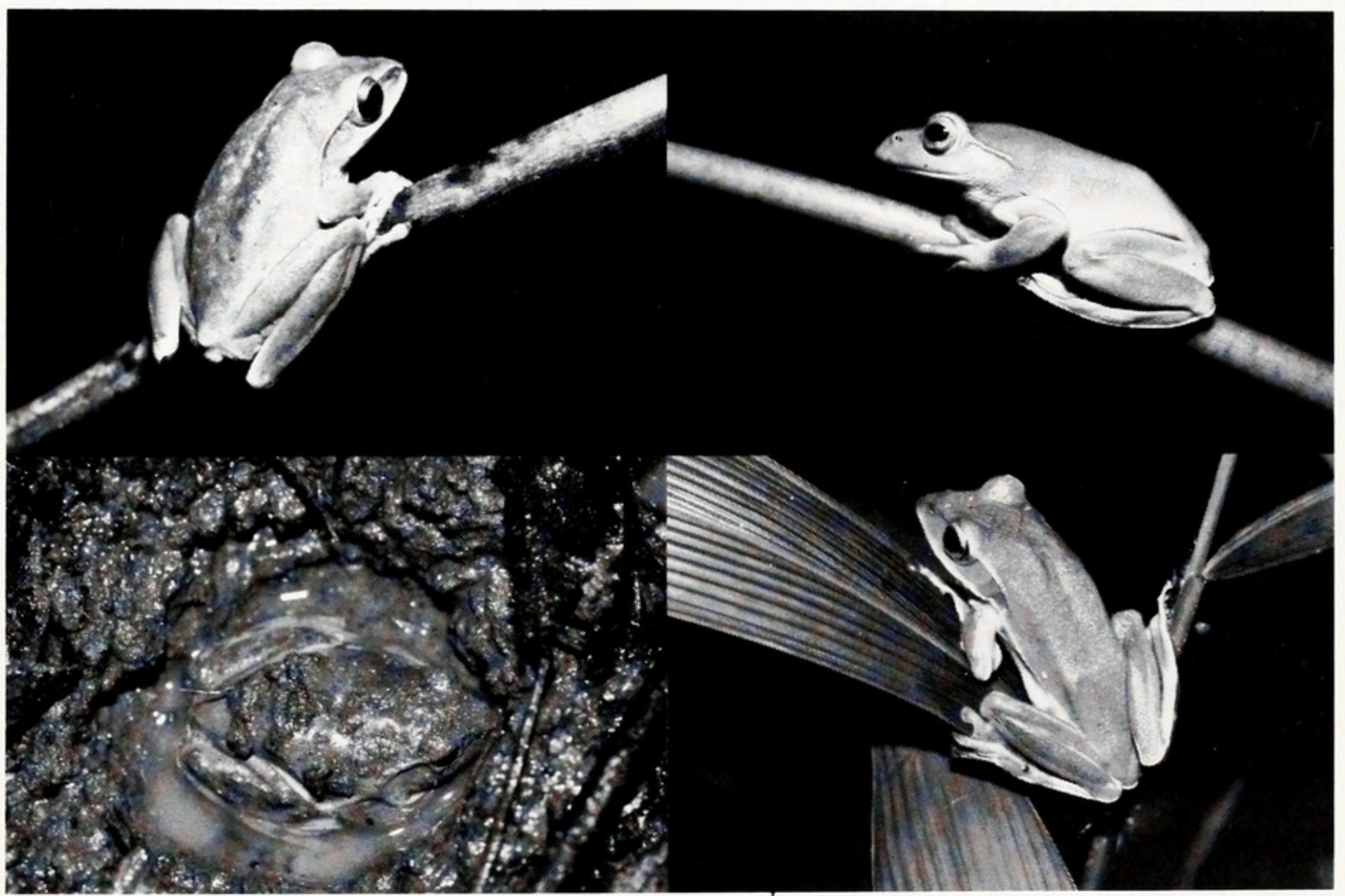

FIG. 1. The species of Polypedates and Rhacophorus on Taiwan: P. megacehalus (upper left), $R$. taipeianus (upper right), $R$. moltrechti (lower left), $P$. prasinatus (lower right).

The emerald tree frog, Rhacophorus prasinatus Mou, Risch and Lue, $1983(=R$. smaragdinus Lue and Mou, 1983), has had an uncertain taxonomic status. When first described, it was thought to be closely related to $R$. chenfui, currently placed in Polypedates (Jiang, Hu and Zhao, 1987), on morphological grounds and to $P$. leucomystax on account of genetic similarity. Having examined the external physical structure, muscular structure and stained skeletons of specimens from the type locality, I conclude that this species should be classified in Polypedates in accordance with the definitions and criteria set forth by Liem (1970) and Jian et al.(1987) to distinguish the genera Rhacophorus and Polypedates. The following are the key features observed:

Dermal fold along outer edges of forearm and above anus in rows of 
tubercles, tarsal fold not evident or absent. Fingers half webbed; web of all toes except the fourth extending beyond subarticular tubercles; fourth toe webbed to middle subarticular tubercle or somewhat beyond. Dorsal view of intercalary cartilage heartshaped. Esophageal and lateral processes of laryngeal apparatus present. M. extensor radialis accessorius lateralis moderately large, originating along lateral side of humerus and inserting on the distodorsal end of radio-ulna; M. extensor brevis superficialis of the first digit present. Vomerine teeth present. Parieto-squamosal arch of the fronto-parietal bone absent. Vertebral column procoelous.

Polypedates prasinatus (Mou, Risch and Lue 1983) comb. nov.

Rhacophorus prasinatus Mou, Risch and Lue, 1983;

Rhacophorus smaragdinus Lue and
Mou, 1983

The two junior synonyms share the same holotype and bear the same publication year. However, the Rhacophorus prasinatus has priority. It was published on 30 December 1983 in Alytes 2(4) which was mailed on that date, as indicated in the journal. Although $R$. smaragdinus has the same publication date in the Journal of Taiwan Museum 36(2), I have learned from the editor, S. F. Hung, that the mailing date of this issue was 17 January 1984. This supports a previous arbitrary adoption of the first junior synonym (Frost, 1985).

In general, Polypedates and Rhacophorus species can be distinguished from the other treefrogs by the Y-shaped terminal phalanx and absence of anterior horns of the hyoid (Liem, 1970). The species in Taiwan (Fig. 1) can be distinguished by the following key:

\section{Key To Species Of Polypedates And Rhacophorus Of Taiwan}

la. Dermal fold along the forearm absent or in rows of tubercles; tarsal fold not evident or absent ....................................................................... (Polypedates)

2a. Skin shagreened, ground color green above; supratympanic fold yellowish brown

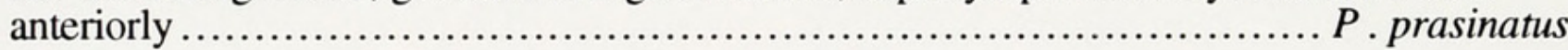

2b. Skin smooth, ground color light brown or brown, usually with dark spots or stripes P. megacehalus

lb. Dermal fold along the forearm and tarsus present (Rhacophorus)

3a. Skin smooth, with black spots or blotches on flanks and inner side of thighs R. moltrechti

3b. Skin shagreened to granulated, with fine dark dots on inner side of thighs.... R. taipeianus

These two genera in Taiwan also exhibit different reproductive modes. Both Polypedates species usually deposit foamy masses suspended on low tree branches overhanging pools or on cistern walls above the water. Egg masses become light brown when the outer foamy substance dries. In contrast, Rhacophorus species deposit foamy egg masses near puddles in holes burrowed by the males or beneath soil or fallen leaves.
Specimens examined: NMNS 0145501459, 18 specimens.

\section{Acknowledgments}

I thank C. K. Starr, G. F. Wu and S. S. Lin for helpful comments and suggestions on the manuscript. I am grateful also to A. Dubois, editor of Alytes, and S. F. Hung of the Taiwan Museum for providing dates of publications relevant to priority. 


\section{References}

FROST, D. R. 1985. Amphibian species of the world. Association of Systematics Collections. Lawrence, Kansas. 732 pp.

JIANG, S., HU, S. AND E. ZhaO. 1987. The approach of the phylogenetic relationship and the supraspecific classification of 14 Chinese species of treefrogs (Rhacophoridae). Acta Herpetologica Sinica 1987, 6(1):27-42. (In Chinese).

LIEM, S. S. 1970. The morphology, systematics, and evolution of the Old World treefrogs (Rhacophoridae and Hyperoliidae). Fieldiana: Zoology 57:1-145.

LUE, K. Y. AND Y. P. MOU. 1983. Rhacophorus smaragdinus (Anura: Rhacophoridae) a new rhacophorid tree frog from Taiwan. Journal of Taiwan Museum. 36(2):15-22.

MOU, Y. P., RISCH, J. P. AND K. Y. LUE. 1983. Rhacophorus prasinatus, a new tree frog from Taiwan, China (Amphibia, Anura, Rhacophoridae). Alytes 2(4):154-162. 


\section{$2 \mathrm{BHL}$ Biodiversity Heritage Library}

Chou, Wen-Hao. 1993. "On the status of Rhacophorus prasinatus Mou, Risch, and Lue (Anura: Rhacophoridae)." Asiatic herpetological research 5, 11-13. https://doi.org/10.5962/bhl.part.8613.

View This Item Online: $\underline{\text { https://www.biodiversitylibrary.org/item/20756 }}$

DOI: https://doi.org/10.5962/bhl.part.8613

Permalink: https://www.biodiversitylibrary.org/partpdf/8613

\section{Holding Institution}

Harvard University, Museum of Comparative Zoology, Ernst Mayr Library

\section{Sponsored by}

Harvard University, Museum of Comparative Zoology, Ernst Mayr Library

\section{Copyright \& Reuse}

Copyright Status: In copyright. Digitized with the permission of the rights holder.

Rights Holder: Asiatic Herpetological Research Society \& Chengdu Institute of Biology, Chinese Academy of Science

License: http://creativecommons.org/licenses/by-nc-sa/3.0/

Rights: https://biodiversitylibrary.org/permissions

This document was created from content at the Biodiversity Heritage Library, the world's largest open access digital library for biodiversity literature and archives. Visit BHL at https://www.biodiversitylibrary.org. 